\title{
Five-year clinical outcomes of drug-eluting stents according to on-label and off-label use
}

Kyu-Hwan Park ${ }^{1}$, Ung Kim ${ }^{1}$, Chan-Hee Lee ${ }^{1}$, Jang-Won Son ${ }^{1}$, Jong-Seon Park ${ }^{1}$, Dong-Gu Shin ${ }^{1}$, Young-Jo $\mathrm{Kim}^{1}$, and Jeong-Hwan $\mathrm{Cho}^{2}$

${ }^{1}$ Division of Cardiology, Department of Internal Medicine, Yeungnam University Medical Center, Daegu; ${ }^{2}$ Division of Cardiology, Department of Internal Medicine, Daegu Veterans Hospital, Daegu, Korea

Received: February 23, 2015

Revised : May 10, 2015

Accepted: June 10, 2015

\section{Correspondence to}

Ung Kim, M.D.

Division of Cardiology, Yeungnam University Medical Center, 170,

Hyeonchung-ro, Nam-gu, Daegu

42415, Korea

Tel: $+82-53-620-3832$

Fax: +82-53-621-3310

E-mail:woongwa@yu.ac.kr
Background/Aims: To compare the clinical outcomes of 'on-label' and 'off-label' drug-eluting stents (DESs) over a 5-year follow-up period.

Methods: A total of 929 patients that underwent percutaneous coronary intervention with DESs were enrolled. Patients were divided into two groups according to on-label $(n=449)$ and off-label $(n=480)$ indications. Off-label use was defined as implantation of DESs for acute myocardial infarction (MI), very small vessel, a long stenotic lesion, chronic total occlusion, a bifurcation lesion, an ostial lesion, left main coronary artery disease, multivessel disease, a saphenous vein graft lesion, and a lesion with thrombus. Endpoints were composite of major adverse cardiac events (MACEs), which included all-cause death, ischemic-driven target vessel revascularization (Id-TVR), MI, and stent thrombosis (ST). Clinical outcomes in the two groups were compared for up to 5 years postimplantation.

Results: At 1 year postimplantation, the off-label group had higher incidences of total MACEs ( $8.2 \%$ vs. $3.7 \%, p=0.005$ ), Id-TVR (5.0\% vs. $1.6 \%, p=0.004)$, and ST $(1.7 \%$ vs. $0.3 \%, p=0.042)$, and at 5 years postimplantation, the off-label group continued to have higher incidences of total MACEs (17.5\% vs. $9.4 \%, p<0.001)$, IdTVR (13.1\% vs. $5.8 \%, p=0.024)$, and ST (2.1\% vs. $0.3 \%, p=0.021)$. Multivessel disease and diabetes were found to be independent risk factors of MACE in patients with an off-label indication.

Conclusions: Patients treated with an on-label DES had better long-term clinical outcomes than those treated with an off-label DES.

Keywords: Off-label use; Drug-eluting stent; Outcome assessment (health care)

\section{INTRODUCTION}

Drug-eluting stents (DESs) have been widely viewed as the gold standard for the treatment of coronary artery diseases since the Food and Drug Administration (FDA) approved use of the first DES in April 2003. Many randomized trials have reported significant reductions in angiographic restenosis and in the need for revascularization in patients treated with a DES. However, long- term outcomes of DESs with respect to the incidences of late and very late stent thrombosis (ST), which can cause myocardial infarction (MI) and even death, remain debatable [1-4]. For these reasons, the FDA concluded that DES implantation has been demonstrated to be safe for only on-label indications. But, in real-world clinical practice, the applications of DESs have been extended beyond on-label indications, based on the assumptions that benefits extend to more complex cases and lesion subsets [5]. 
Several studies have been conducted on the clinical outcomes of off-label DES use, but the clinical follow-up data used was limited to 1 year [6-9]. Accordingly, this study was undertaken to compare the clinical outcomes of DESs implanted for on-label and off-label indications over a period of 5 years.

\section{METHODS}

\section{Study populations}

A total of 929 consecutive patients underwent percutaneous coronary intervention (PCI) with a DES from April 2005 to December 2007 at Yeungnam University Medical Center for the treatment of coronary artery disease, and who provided consent were enrolled in this retrospective study. Patients were treated with one of the following DESs; Cypher (sirolimus-eluting coronary stent [SES], Cordis, Warren, NJ, USA), Taxus (paclitaxel-eluting coronary stent [PES], Boston Scientific, Natick, MA, USA) or Endeavor (zotarolimus-eluting coronary stent [ZES], Medtronic, Santa Rosa, CA, USA). On-label indications were for symptomatic ischemic heart disease by de novo lesions $\leq 30 \mathrm{~mm}$ long in native coronary arteries of diameter $\geq 2.5$ to $\leq 3.5 \mathrm{~mm}$ (Cypher), lesions $\leq$ $28 \mathrm{~mm}$ long in arteries of diameter $\geq 2.5$ to $\leq 3.75 \mathrm{~mm}$ (Taxus), and lesions $\leq 35 \mathrm{~mm}$ long in arteries of diameter $\geq 2.25$ to $\leq 4.2 \mathrm{~mm}$, including those with diabetes mellitus (Endeavor) [10-12]. Off-label use was defined as DES use, according to the manufacturer's instructions, for a lesion or patient subset not extensively studied in randomized trials and without FDA approval, and included acute $\mathrm{MI}(<48$ hours), very small vessel $(<2.5 \mathrm{~mm})$, long stenotic lesions $(>30 \mathrm{~mm})$, chronic total occlusions, bifurcation lesions, ostial lesions ( $<5 \mathrm{~mm}$ from orifice), left main coronary artery diseases, multivessel diseases, saphenous vein graft lesions, and lesions with thrombus $[6,9]$. The 929 patients were divided into two groups according to the on-label group $(n=449)$ and the off-label group $(n=480)$ indications.

\section{Percutaneous coronary intervention}

Decisions regarding the types of DESs used were made by respective operators. Prior to PCI, all patients received a $300 \mathrm{mg}$ of aspirin and 300 or $600 \mathrm{mg}$ of clopidogrel if not already on a maintenance dose or unknown.
Unfractionated heparin boluses of 5,000 U were initially administered intravenously and then additional heparin boluses were given to maintain a targeting activated clotting time of 250 to 300 seconds during PCI. Coronary angiography and stenting were performed using routine methods. Daily $100 \mathrm{mg}$ of aspirin and $75 \mathrm{mg}$ of clopidogrel were continued for at least 6 months postimplantation regardless of the stent type. Durations of dual antiplatelet agent administration were determined by physician's discretion based on the recommendations of the American College of Cardiology/American Heart Association [13].

\section{Outcome parameters and clinical follow-up}

Baseline characteristics and laboratory findings were collected. Left ventricular ejection fraction (LVEF) was measured by transthoracic echocardiography during index hospitalization. Procedural data, including the type and number of stents implanted, target lesion sites, and quantitative coronary angiography data (lesion length, stent diameter, and stent length) were assessed by the operator.

The endpoints of this study were composite of major adverse cardiac events (MACEs), which were defined as all-cause deaths, MI, ischemic-driven target vessel revascularization (Id-TVR), and ST. All-cause death was defined as the sum of cardiac and noncardiac deaths, which meant death that was not primarily due to cardiac causes. MI was defined as the presence of at least two of the following: anginal pain, elevation of creatine kinase to more than 3 times the upper limit of normal, and electrocardiographic changes suspicious for MI. Id-TVR was defined as intervention for chest pain or a positive test for ischemia (exercise stress test, stress echocardiogram, resting electrocardiographic evidence of ST-segment deviation in more than 1 lead, or a radionuclide study showing a reversible defect) [14]. ST was classified as 'definite' or 'probable' as proposed by the Academic Research Consortium, according to which definite ST refers to the presence of thrombus in a stent documented by angiography, and probable ST means any MI related to documented acute ischemia in the territory of an implanted stent without angiographic confirmation, or sudden or unexplained death within 30 days of implantation [15].

Overall clinical outcomes were determined by com- 
Table 1. Baseline clinical, laboratory, and procedural characteristics

\begin{tabular}{|c|c|c|c|}
\hline Variable & On-label $(\mathrm{n}=449)$ & Off-label $(n=480)$ & $p$ value \\
\hline Age, yr & $64 \pm 12$ & $64 \pm 11$ & 0.376 \\
\hline Male sex & $296(65.9)$ & $328(68.3)$ & 0.435 \\
\hline Body mass index, $\mathrm{kg} / \mathrm{m}^{2}$ & $23.57 \pm 2.83$ & $24.13 \pm 4.02$ & 0.142 \\
\hline \multicolumn{4}{|l|}{ Previous medical history } \\
\hline CVA & $23(5.1)$ & $20(4.2)$ & 0.488 \\
\hline MI & $22(5.0)$ & $31(6.5)$ & 0.326 \\
\hline PCI & $54(12.0)$ & $58(12.1)$ & 0.979 \\
\hline CABG & $2(0.4)$ & $5(1.0)$ & 0.294 \\
\hline Current smoker & $142(31.6)$ & $129(26.9)$ & 0.111 \\
\hline Diabetes mellitus & $112(24.9)$ & $164(34.2)$ & 0.002 \\
\hline Hypertension & $208(46.3)$ & $247(51.5)$ & 0.118 \\
\hline Total cholesterol, mg/dL & $194.99 \pm 47.71$ & $194.48 \pm 40.60$ & 0.915 \\
\hline $\mathrm{LDL}-\mathrm{C}, \mathrm{mg} / \mathrm{dL}$ & $123 \pm 41$ & $123 \pm 36$ & 0.994 \\
\hline Creatinine, $\mathrm{mg} / \mathrm{dL}$ & $0.99 \pm 0.46$ & $1.72 \pm 8.02$ & 0.254 \\
\hline LVEF, \% & $56 \pm 11$ & $52 \pm 12$ & 0.001 \\
\hline \multicolumn{4}{|l|}{ Previous medication history } \\
\hline Aspirin & $434(97.1)$ & $465(97.1)$ & 0.990 \\
\hline Clopidogrel & $409(91.5)$ & $435(90.8)$ & 0.714 \\
\hline Ticlopidine & o & $1(0.2)$ & 0.334 \\
\hline Cilostazol & $22(4 \cdot 9)$ & $39(8.1)$ & 0.048 \\
\hline$\beta$-Blocker & $292(65 \cdot 3)$ & $330(68.9)$ & 0.248 \\
\hline Nitrate & $234(52 \cdot 3)$ & $248(51.8)$ & 0.861 \\
\hline HMG-CoA reductase inhibitor & $141(31.5)$ & $138(28.8)$ & 0.365 \\
\hline Stent type & & & $<0.001$ \\
\hline Cypher & $254(56.8)$ & $328(68.1)$ & \\
\hline Taxus & $130(29.0)$ & $125(26.0)$ & \\
\hline Endeavor & $64(14 \cdot 2)$ & $28(5.8)$ & \\
\hline Lesion length, mm & $18.84 \pm 7.03$ & $27.28 \pm 13.50$ & 0.001 \\
\hline Stent diameter, mm & $3.16 \pm 0.38$ & $3.06 \pm 0.36$ & $<0.001$ \\
\hline Stent length, mm & $21.9 \pm 6.8$ & $32.2 \pm 15$ & $<0.001$ \\
\hline Total stent number & $1.03 \pm 0.17$ & $1.25 \pm 0.47$ & $<0.001$ \\
\hline
\end{tabular}

Values are presented as mean $\pm \mathrm{SD}$ or number (\%).

CVA, cerebrovascular attack; MI, myocardial infarction; PCI, percutaneous coronary intervention; CABG, coronary artery bypass graft; LDL-C, low density lipoprotein cholesterol; LVEF, left ventricular ejection fraction; HMG-CoA, 3-hydroxy-3-methylglutaryl-coenzyme A.

prehensively reviewing medical records at routine outpatient visits or by telephone interview during the 5-year follow-up period. A committee independently adjudicated all clinical events. Clinical follow-up data was available for all 929 study subjects.

\section{Statistical analysis}

Results were reported as mean \pm standard deviation for numerical variables and as frequencies and percentages for categorical variables. The independent $t$ test was used to compare group continuous variables, and the chisquare test or Fisher exact test was used to compare cat- 
Table 2. Off-label indications for drug-eluting stent implantation

\begin{tabular}{lc}
\hline Lesion & Percentage \\
\hline Acute myocardial infarction & 46.0 \\
Chronic total occlusion & 20.6 \\
Long stenotic lesion $(>30 \mathrm{~mm})$ & 17.0 \\
Multivessel disease & 8.5 \\
Ostial lesion (<5 mm from orifice) & 1.9 \\
Left main coronary artery disease & 1.9 \\
Bifurcation lesion & 1.1 \\
Lesion with thrombus & 0.4 \\
Very small vessel $(<2.25 \mathrm{~mm})^{\text {Saphenous vein graft lesion }}$ & 0.2 \\
Total $^{\mathrm{a}}$ & 0.1 \\
\hline
\end{tabular}

${ }^{a} 22.1 \%$ of the patients had more than two off-label indications.

egorical variables. Incidences of MACE, all-cause death, Id-TVR, MI, and ST in the two groups were determined using Kaplan-Meier event curves, and compared using log-rank tests. Multivariate logistic regression analysis was used to identify predictors of MACE in the off-label group. SPSS version 18.0 (SPSS Inc., Chicago, IL, USA) was used for the statistical analysis, and statistical significance was accepted for $p$ values $<0.05$.

\section{RESULTS}

\section{Baseline characteristics including angiographic and procedural data}

Of the 929 study subjects, 710 patients were completely monitored for 5 years (follow-up rate, 76.4\%). The baseline clinical characteristics of the on- and off-label groups are shown in Table 1. The groups were similar in terms of age, sex, previous medical history, smoking, hypertension, and low density lipoprotein cholesterol level. However, the on-label group had a lower prevalence (24.9\% [n = 112] vs. $34.2 \%[n=164], p=0.002)$ and higher LVEF value $(56 \% \pm 11 \%$ vs. $52 \% \pm 12 \%, p=0.001)$. More patients in the off-label group were taking cilostazol $(8.1 \%[n=39]$ vs. $4.9 \%[n=22], p=0.048)$, but no significant intergroup difference was found for using of other periprocedural medicines, including other antiplatelet drugs (aspirin, clopidogrel, and ticagrelor), $\beta$-blocker, nitrate, or 3-hydroxy-3-methylglutaryl-coenzyme A reductase inhibitor.

Four hundred eighty patients (51.6\%) were treated using off-label indications (Table 2) and $22.1 \%$ of the patients had more than two off-label indications. The most two common off-label indications were acute MI ( $\mathrm{n}=$ $221,46.0 \%)$ and chronic total occlusion $(n=381,20.6 \%)$. Stent types and sites of implantation are listed in Table 1. In terms of procedural data, marked differences were observed between the two groups; the off-label group had a longer mean lesion length, a larger mean stent
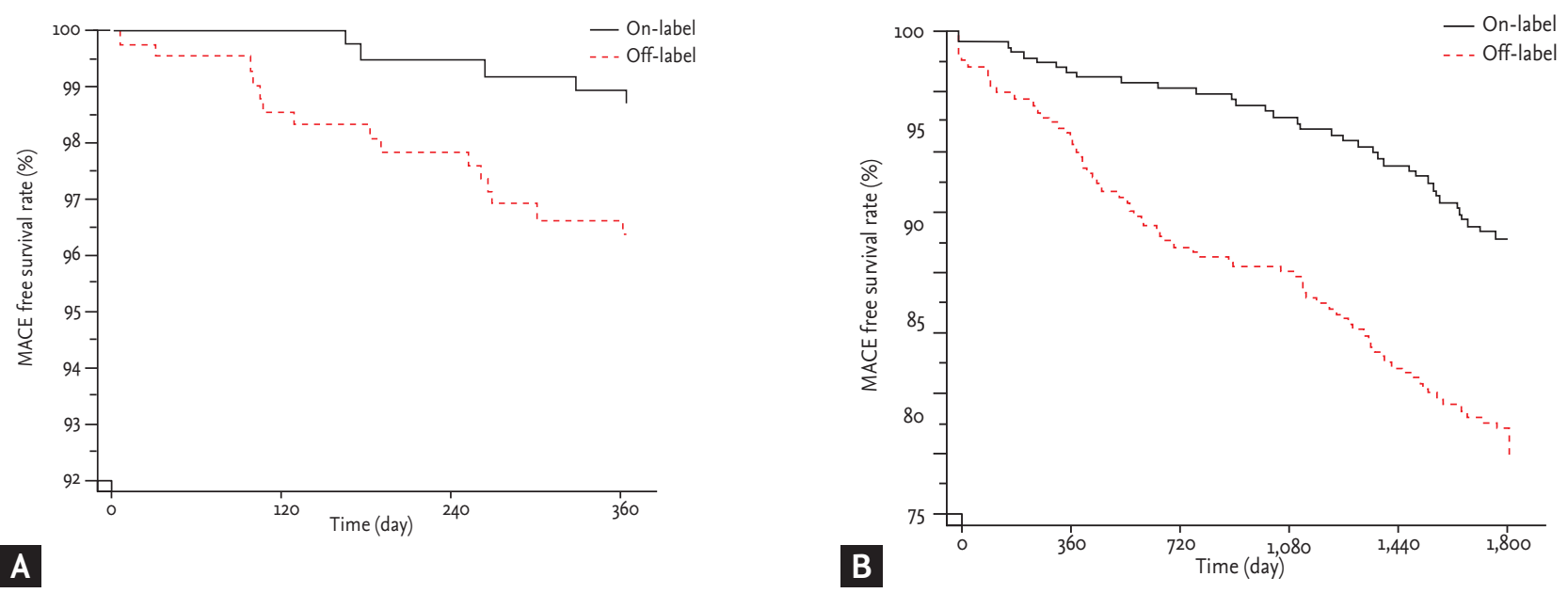

Figure 1. Major adverse cardiac event (MACE) free survival curve at (A) 1 year and (B) cumulative 5 years. The on-label group had significantly higher event-free survival rates at 1 year clinical follow-up and cumulative 5 years clinical follow-up as shown in $\mathrm{A}(p=0.001)$ and $\mathrm{B}(p=0.001)$. 
Table 3. Clinical outcomes during 5 years of follow-up between two groups

\begin{tabular}{|c|c|c|c|c|c|c|}
\hline \multirow{2}{*}{ Variable } & \multicolumn{3}{|c|}{ 1-Year } & \multicolumn{3}{|c|}{ 5-Year } \\
\hline & On-label & Off-label & $p$ value & On-label & Off-label & $p$ value \\
\hline MACE & $16(3.7)$ & $38(8.2)$ & 0.005 & $34(9.4)$ & $84(17 \cdot 5)$ & $<0.001$ \\
\hline All-cause death & $10(2.2)$ & $14(2.9)$ & 0.515 & $10(2.2)$ & $16(3 \cdot 3)$ & 0.241 \\
\hline MI & $2(0.4)$ & $5(1.0)$ & 0.296 & $13(2.9)$ & $26(5 \cdot 4)$ & 0.603 \\
\hline Id-TVR & $7(1.6)$ & $24(5.0)$ & 0.004 & $29(5.8)$ & $63(13.1)$ & 0.024 \\
\hline $\mathrm{ST}$ & $1(0.3)$ & $7(1.7)$ & 0.042 & $1(0.3)$ & $9(2.1)$ & 0.021 \\
\hline
\end{tabular}

Values are presented as number (\%).

MACE, major adverse cardiac event; MI, myocardial infarction; Id-TVR, ischemic-driven target vessel revascularization; ST, stent thrombosis.

Table 4. Independent risk factors for long-term major adverse cardiac event in patients with off-label indication

\begin{tabular}{|c|c|c|c|}
\hline Factor & Hazard ratio & $95 \% \mathrm{CI}$ & $p$ value \\
\hline Diabetes mellitus & 1.65 & $1.09-2.49$ & 0.017 \\
\hline Long stenotic lesion (> $30 \mathrm{~mm}$ ) & 1.58 & $0.90-2.21$ & 0.131 \\
\hline Chronic total occlusion & 1.21 & $0.75^{-1.97}$ & 0.423 \\
\hline Bifurcation lesion & 2.90 & $0.73-1.45$ & 0.127 \\
\hline Ostial lesion (<5 mm from orifice) & 1.39 & $0.38-5.06$ & 0.615 \\
\hline Left main coronary artery disease & 0.25 & $0.03-2.10$ & 0.200 \\
\hline Multivessel disease & 2.00 & $1.25-3.22$ & 0.004 \\
\hline Myocardial infarction & 1.91 & $0.84-1.91$ & 0.243 \\
\hline
\end{tabular}

CI, confidence interval.

length, a smaller mean stent diameter, and more stents. These differences seemed to be natural consequences of following off-label indications.

\section{One- and five-year outcomes}

Over the first year postimplantation; total MACEs (8.2\% $[\mathrm{n}=38]$ vs. $3.7 \%[\mathrm{n}=16], \mathrm{p}=0.005), \operatorname{Id}-\operatorname{TVR}(5.0 \%[\mathrm{n}=24]$ vs. $1.6 \%[\mathrm{n}=7], p=0.004)$, and ST $(1.7 \%[\mathrm{n}=7]$ vs. $0.3 \%[\mathrm{n}$ $=1], p=0.042$ ) were significantly higher in the off-label group, and rates of all-cause death and MI were non-significantly higher in off-label group. Similar tendencies were observed over the 5-year postimplantation period; total MACEs (17.5\% [n = 84] vs. 9.4\% $[\mathrm{n}=34], \mathrm{p}<0.001)$, $\operatorname{Id}-\operatorname{TLR}(13.1 \%[\mathrm{n}=63]$ vs. $5.8 \%[\mathrm{n}=29])$, and ST $(2.1 \%[\mathrm{n}=$ 9] vs. $0.3 \%[\mathrm{n}=1], p=0.021$ ) (Table 3 ).

MACE-free survival curves for the two groups at 1 year and at 5 years are shown in Fig. 1. For both periods, the on-label group had significantly higher event-free survival rates $(p=0.001)$. Multivariable analysis showed that multivessel disease (hazard ratio [HR], 2.00; 95\% confi- dence interval [CI], 1.09 to $2.49 ; p=0.004)$ and diabetes (HR, 1.65; 95\% CI, 1.25 to 3.22; $p=0.017$ ) were significant risk factors of long-term MACE in the off-label group (Table 4).

\section{DISCUSSION}

The results of this study showed that the long-term clinical outcomes of off-label DESs use were worse than those of on-label DESs use. However, over the 1 year and the first 5 years postimplantation MACE, Id-TVR, and ST rates were higher in off-label group. On the other hand, all-cause deaths and the incidences of MI were not significantly different in the two groups, though numerically higher in the off-label group. These cumulative results concur with those of previous studies. Qasim et al. [6] showed patients that underwent off-label DES implantation at a single center between April 2002 and April 2006 had higher rates of TVR (13.2\% vs. $24.1 \%, p$ 
$=0.0001)$ and MACEs (17.6\% vs. $28.2 \%, p=0.0001)$. Kotani et al. [16] found off-label use did not increased the rates of death or MI, but that off-label use was associated with higher rates of target lesion revascularization, non-target lesion TVR, and total MACEs (10.3\% vs. 5.1\%, $p=0.030 ; 10.1 \%$ vs. $4.8 \%, p=0.007 ; 24.0 \%$ vs. $18.0 \%, p=$ 0.005 ; respectively).

The Deutsches Drug-Eluting Stent [17] and the EVENT (Evaluation of Drug Eluting Stents and Ischemic Events) Registry [8] were the first to examine the clinical outcomes of off-label DES use. In both of these multicenter trials, it was concluded that off-label DES use is associated with higher rates of adverse events including death ( $4.3 \%$ vs. $2.6 \%$ and $3.1 \%$ vs. $2.1 \%$, respectively) and MI (2.7\% vs. $1.9 \%$ and $11 \%$ vs. $5.3 \%$, respectively) compared to on-label use. In one single center retrospective study [7], no remarkable differences in MACEs (off-label 2.3\% vs. on-label 3.0\%) or TVR (off-label 1.3\% vs. on-label 1.0\%) were found after adjusting for possible confounders.

However, majority of the findings mentioned above were derived from evaluations of first generation DESs, which have since been replaced by new generation DESs in clinical practice. Furthermore, follow-ups were relatively short at less than 2 years. Galasso et al. [18] performed a study using a newer generation DES (Endeavor Resolute, which was designed to improve clinical outcomes in patients with more complex coronary artery diseases) to evaluate the safety and efficacy of its off-label use, and concluded its off-label use was not associated with an increased risk of MACE (9.4\% vs. 3.4\%, $p=0.13$ ), death (4.9\% vs. $0.0 \%, p=0.38)$, or TVR (5.5\% vs. $3.4 \%, p$ $=0.75$ ) over a mean follow-up of 17 months. Serruys et al. [19] examined performance of the second generation everolimus-eluting stent, and included a large number of off-label indications, and obtained MACE, TVR, death, and MI rates of $8.7 \%, 4.9 \%, 1.6 \%$, and $13.5 \%$, respectively, at 1 year. Nevertheless, data on the clinical outcomes of new generation DESs is scant.

Our study included the evaluation of the effect about new generation DES on on-label and off-label indication as well as first generation DES, albeit the number of patients treated with newer generation DESs (Endeavor) was small. In fact, the majority of cardiologists have been choosing newer generation DES for treating coronary artery diseases without regard to on-label and off-label indications in contemporary practice and those clinical outcomes data are encouraging.

In the present study, the incidences of MACE and Id-TVR were found to be higher in the off-label group. However, these differences were probably caused the inclusion of lesions of greater complexity, such as longer lesions, smaller diameter coronary vessels, chronic totally occlusive lesions, and other challenging situations like acute MI, included in the off-label group. Furthermore, it can be assumed that the greater proportion of diabetic patients in the off-label group had adverse effects on 1- and 5-year clinical outcomes. The restenosis rate in diabetic patients treated with DES was almost $40 \%$, and the odds ratio of restenosis associated with DM was 1.61 (95\% CI, 1.21 to $2.14 ; p=0.004$ ). Furthermore, neointimal hyperplasia is known to be strongly correlated with the occurrence of stent-related cardiovascular events [20].

The present study has several limitations that warrant consideration. First, it was conducted retrospectively in a single center. Second, the number of patients treated with a newer generation DES (Endeavor) was small and the proportions so treated differed in the two groups. Third, we did not record prescribed durations of compliance with antiplatelet drugs, and thus, the effects of compliance on clinical outcome, which may be one of the major determinant of ST and other adverse events, were not considered.

In conclusion, patients treated with DESs, which included SES, PES, and ZES, for on-label indications, achieved better short- and long-term clinical outcomes in terms of MACEs, Id-TVR, and ST over a 5-year follow-up. Furthermore, diabetes and multivessel disease were found to be significant, independent risk factors of long-term MACEs in patients treated with a DES for off-label indications.

\section{KEY MESSAGE}

1. Patients treated with an on-label drug-eluting stent (DES) had better long-term clinical outcomes than those treated with an off-label DES.

2. Multivessel disease and diabetes were found to be independent risk factors of major adverse cardiac event in patients with an off-label indication. 


\section{Conflict of interest}

No potential conflict of interest relevant to this article was reported.

\section{Acknowledgments}

This work was supported by Yeungnam University.

\section{REFERENCES}

1. Spaulding C, Daemen J, Boersma E, Cutlip DE, Serruys PW. A pooled analysis of data comparing sirolimus-eluting stents with bare-metal stents. N Engl J Med 2007;356:989-997.

2. Moses JW, Leon MB, Popma JJ, et al. Sirolimus-eluting stents versus standard stents in patients with stenosis in a native coronary artery. N Engl J Med 2003;349:1315-1323.

3. Stone GW, Moses JW, Ellis SG, et al. Safety and efficacy of sirolimus- and paclitaxel-eluting coronary stents. N Engl J Med 2007;356:998-1008.

4. Kimura T, Morimoto T, Nakagawa Y, et al. Very late stent thrombosis and late target lesion revascularization after sirolimus-eluting stent implantation: five-year outcome of the j-Cypher Registry. Circulation 2012;125:584-591.

5. Roy P, Buch AN, Javaid A, et al. Impact of "off-label" utilization of drug-eluting stents on clinical outcomes in patients undergoing percutaneous coronary intervention. Am J Cardiol 2008;101:293-299.

6. Qasim A, Cosgrave J, Latib A, Colombo A. Long-term follow-up of drug-eluting stents when inserted for on- and off-label indications. Am J Cardiol 2007;100:1619-1624.

7. Poorhosseini H, Kassaian SE, Aghajani H, et al. On-label and off-label use of drug-eluting stents: comparison of short- and long-term outcomes. Tex Heart Inst J 2012;39:24-29.

8. Win HK, Caldera AE, Maresh K, et al. Clinical outcomes and stent thrombosis following off-label use of drug-eluting stents. JAMA 2007;297:2001-2009.

9. Brodie BR, Stuckey T, Downey W, et al. Outcomes and complications with off-label use of drug-eluting stents: results from the STENT (Strategic Transcatheter Evaluation of New Therapies) group. JACC Cardiovasc Interv 2008;1:405-414.
10. Windecker S, Remondino A, Eberli FR, et al. Sirolimus-eluting and paclitaxel-eluting stents for coronary revascularization. N Engl J Med 2005;353:653-662.

11. Stone GW, Ellis SG, Cox DA, et al. A polymer-based, paclitaxel-eluting stent in patients with coronary artery disease. N Engl J Med 2004;350:221-231.

12. Food and Drug Administration. Resolute integrity zotarolimus coronary stent system [Internet]. Silver Spring (MD): Food and Drug Administration, 2015 [cited 2015 Dec 4]. Available from: http://www.accessdata.fda.gov/cdrh_docs/ pdfi1/p110013Soo5a.pdf.

13. Levine GN, Bates ER, Blankenship JC, et al. 2011 ACCF/ AHA/SCAI guideline for percutaneous coronary intervention: a report of the American College of Cardiology Foundation/American Heart Association Task Force on Practice Guidelines and the Society for Cardiovascular Angiography and Interventions. Circulation 2011;124:e574-e651.

14. Singh M, Gersh BJ, McClelland RL, et al. Predictive factors for ischemic target vessel revascularization in the Prevention of Restenosis with Tranilast and its Outcomes (PRESTO) trial. J Am Coll Cardiol 2005;45:198-203.

15. Cutlip DE, Windecker S, Mehran R, et al. Clinical end points in coronary stent trials: a case for standardized definitions. Circulation 2007;115:2344-2351.

16. Kotani J, Ikari Y, Kyo E, Nakamura M, Yokoi H. Long-term outcomes following off-label use of sirolimus-eluting stent. J Cardiol 2013;62:151-157.

17. Bauer T, Nienaber CA, Akin I, et al. Comparison between on-label versus off-label use of drug-eluting coronary stents in clinical practice: results from the German DES. DE-Registry. Clin Res Cardiol 2011;100:701-709.

18. Galasso G, Piccolo R, Cassese S, et al. Unrestricted use of endeavor resolute zotarolimus-eluting stent in daily clinical practice: a prospective registry. J Invasive Cardiol 2012;24:251-255.

19. Serruys PW, Silber S, Garg S, et al. Comparison of zotarolimus-eluting and everolimus-eluting coronary stents. $\mathrm{N}$ Engl J Med 2010;363:136-146.

20. Gilbert J, Raboud J, Zinman B. Meta-analysis of the effect of diabetes on restenosis rates among patients receiving coronary angioplasty stenting. Diabetes Care 2004;27:990994 . 